\title{
Continuous Casting of Steel-Actual and Future Aspects*
}

\author{
By Ulrich PETERSEN**
}

\section{Synopsis}

The experiment is made to outline the actual state and the future development of the continuous casting of steel, based on the long standing development work and experience with the casting of almost 5 million tons of steel produced in the continuous casting machines of Mannesmann. A general view of the wide ranging programme of steel grades informs about the actual state.

The different types of continuous casting machines today in operation are discussed as well as technical points of view, as breakouts, mould construction, strand cooling, powder casting and scarfing questions.

Further discussions touch upon the advantages of continuous casting with regard to steel quality, yield, material flow, possibilities of rationalization and the harmonic integration of continuous casting machines in steel works.

Final views to future development deal with questions of automation, future design of continuous casting machines and the casting of hollow strands for the fabrication of seamless tubes.

\section{Introduction}

Today continuous casting of steel has succeeded to take a firm place among the metallurgical processes. ${ }^{1,2), 3)}$ With regard to its importance for the iron and steel industry, it may be compared to the basic oxvgen steelmaking process. The highly efficient basic oxygen steelmaking process simply asks for equally efficient methods of casting the produced steel quickly and economically. Here continuous casting comes in as the ideal completion which offers inherent possibilities of rationalization and cost reduction.

Already at an early stage Mannesmann enrolled in these developments, i.e. in the basic oxygen steelmaking and, in particular, the continuous casting of steel. Therefore this report on the actual and the future development of the continuous casting of steel is based on the solid experience gained in the continuous casting of almost 5 million tons of various sections and qualities on machines of various types. The fact that more than $75 \%$ of our steel are, at present, produced by the LD and LDAC process and that about $60 \%$ of this steel are continuously cast is symptomatic of this development.

\section{Early Developments and Present Status at the Mannesmann $A G$}

The development of continuous casting at Mannesmann goes back to $1950.4^{4), 51,6)}$ First basic research work regarding the reliability of the continuous casting of steel was done on a single-strand vertical type continuous casting machine for billets put into operation in 1950. This machine was expanded in 1954 to a four-strand semi-industrial caster. ${ }^{71,8), 91}$

On the basis of such research work and experience soon licenses were granted for the construction of industrial continuous casting machines outside the Mannesmann group. In our own works, since 1957, con- tinuous casting has been included in our investment programmes as a means of casting tonnage steels. At the end of 1962 a vertical type continuous casting machine for billets up to $300 \mathrm{~mm}$ and slabs up to $1.50 \mathrm{~m}$ width came into operation in our Grillo Funke works in Gelsenkirchen which absorbed the complete output of four open hearth furnaces with a capacity of 60 or 80 $t$ each. ${ }^{10)}$ More than 1 million tons of steel have been cast on this machine when the steelmaking facilities at Gelsenkirchen were shut down to concentrate steel making at our Huckingen works in the middle of 1968. Today the machine is operating again in one of the Huckingen steel plants.

In September 1964, the prototype of a single strand oval bow-type continuous casting machine for slabs up to $2.10 \mathrm{~m}$ width was put into operation in combination with 160-t open hearth furnaces, ${ }^{10)}$ thus giving us the knowledge and experience for additional bow type machines which we intended to install in the BOF shop with its 220-t converters. In the middle of 1967, two oval bow-type machines with two strands each designed for slabs between 0.80 and $2.10 \mathrm{~m}$ width started production, supplying today the major part of our continuously cast material. ${ }^{11)}$

As mentioned before there is in addition the vertical type continuous casting machine from our Gelsenkirchen steel plant. The machine was re-commissioned at Huckingen at the beginning of this year and is essentially fed with steel from the LDAC steelmaking plant with its 40-t converters and from a 45-t electric arc furnace. It has been adapted to the Huckingen requirements and expanded to comprise casting facilities for hollow strands. Thus, all steelmaking divisions at Huckingen have the possibility of continuously casting substantial parts of their production.

The scale of continuously cast qualities today covers ordinary structural steel as well as aluminium-killed steels for the highest deep-drawing grades. ${ }^{11}$ Table 1 shows the total quantities of the various steel grades produced up to March 1970 on the continuous casting machines of Mannesmann and their respective classification corresponding to DIN, ASTM, ABS and API specifications. It furthermore shows the kind of application the material was supplied for. The figure also indicates that of each of the most interesting qualities, such as steels for boiler plates and ship building, high-strength structural steels, steels for welded largediameter pipes and deep drawing grades, quantities of several $100000 \mathrm{t}$ have already been continuously cast. 
Table 1. Steel grades continuously cast at Mannesmann AG as of March 1970

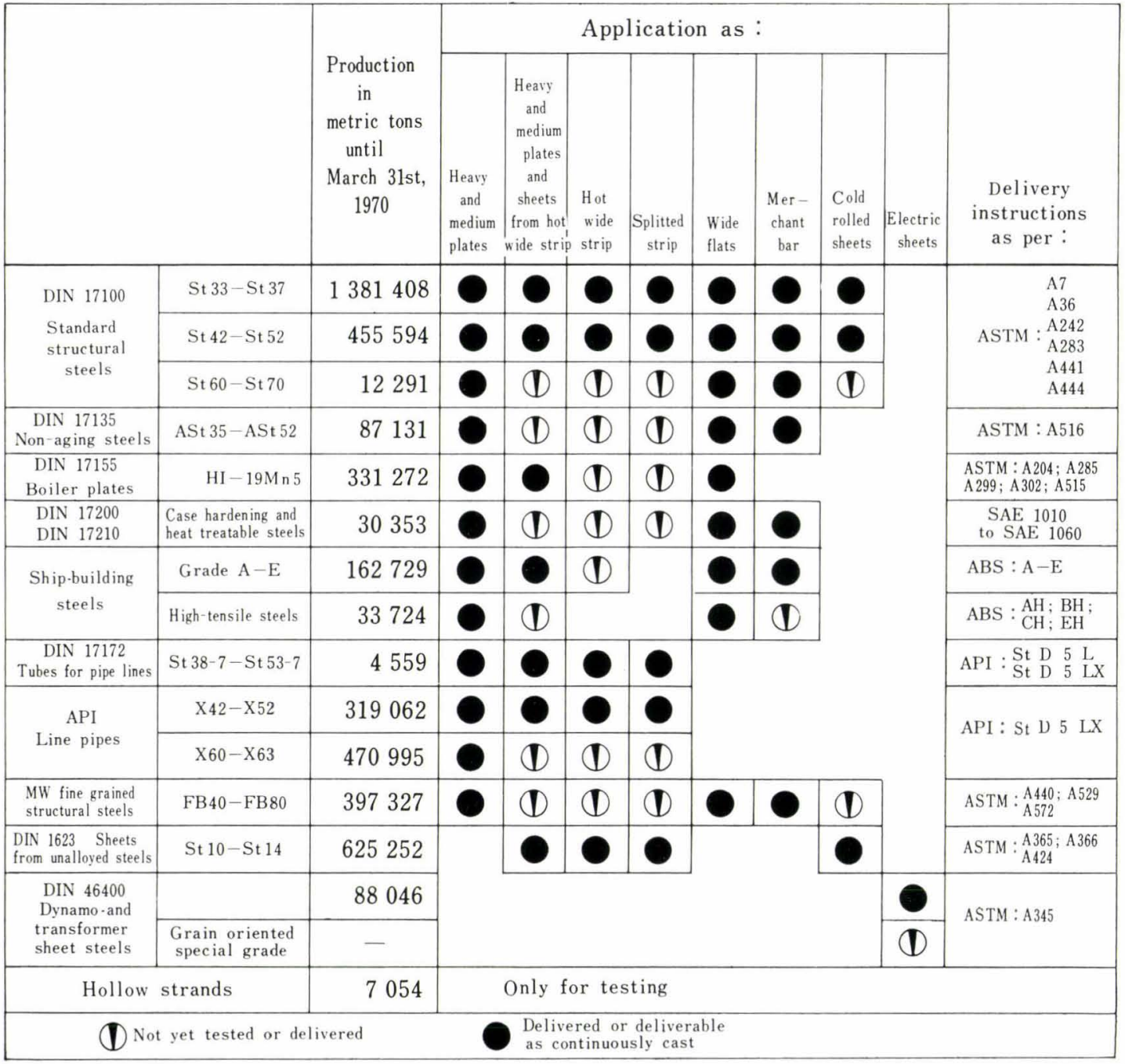

\section{Advantages of Continuous Casting}

From a principal comparison of continuous casting with the conventional ingot casting methods as shown in Fig. 1, it appears that continuous casting of steel is more complicated than ingot casting.

If, in spite of that, continuous casting is increasingly preferred today, this is due to reasonable advantages of continuous casting.

In this connection, the factor quality should be mentioned first. It stands to reason that with the introduction of continuous casting quality standard must at least be maintained. This may mean that steelmaking practices must be adjusted to continuous casting. While ingots of increasing sizes show increasing transversal and longitudinal segregation, continuously cast strands the sizes of which correspond to roughed-down material have either none or very little segregation in the strand section and none at all over the strand length. This advantage of continuously cast material cannot be overestimated, as it offers the possibility of substantially enlarging the field of application of such steel grades which are susceptible to segregation.

Planning of the individual orders normally begins at the steelplant. In conventional casting, orders are

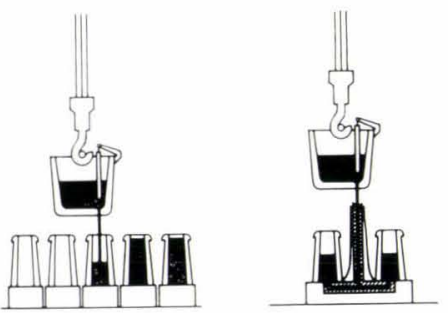

Top pouring
Bottom pouring

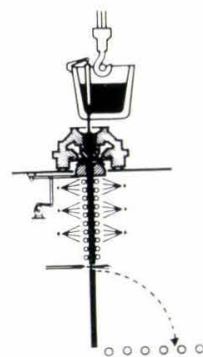

Continuous casting
Fig. 1. Ingot casting and continuous casting

combined in such a way to ensure the best possible use of the slabs and blooms resulting from a given mould size. This requires large mould inventories as many moulds are not currently used. Only on rare occasions it is possible to fully budget a bloom. In most cases a certain overweight and the resulting yield loss must be put up with.

Here again, continuous casting is much more rational. By varying length and width of the strand, any weight desired by the rolling mills can be produced. By means of the quick adjusting system for continuous 
casting moulds developed by Mannesmann, which has proved successful in current operation, the width can be changed for each individual heat without prolongation of the setting time so that there is no need for mould changing and the respective mould inventory. By aid of the adjustable mould the feed for hot strip mills for instance can be cast in any required width. This means less edging compared to conventionally cast ingots which, to keep the mould inventory to an economic size, are cast to certain steps of widths only.

Another advantage over conventional casting is the limitation of overweight to one piece of one strand. Also in multi-strand machines all strands can be cast to just the required weight and then be shut off, with the remaining steel going into one strand only.

Furthermore, the continuously cast section is true to size and has an exact weight per meter. Such accuracy cannot be achieved in rolling conventionally cast ingots. To prevent shortages at the finishing train, corresponding allowances are made for conventional slabs and blooms; which means, in the last consequence, a lower yield.

The same unfavourable effect is produced in conventional ingot casting by the impossibility to accurately forecast the amount of piping. If there is more piping than expected, this will result in slabs or blooms having underweight. Nor does it help if there is less piping than expected, as the resulting plus of good material has not been budgeted. These problems again are inexistent in continuous casting.

The geometric accuracy of the continuously cast sections offers other advantages which elude quantitative definition. If duly cooled down, a flatness is obtained which can never be achieved by roughing down conventionally cast material. Because of these properties, continuously cast material is more easily handled and stored and facilitates its subsequent processing. Because of its exact size and straightness it is particularly indicated for induction heating, a method that surely will gain more and more importance in the future.

Another factor clearly effecting the profitability is the improved yield of continuous casting due to the smaller scrap amount. ${ }^{12)}$ It may be said that the yield of good strands related to the molten steel in the ladle is-depending on strand section and amount of conditioning-about 10 to $15 \%$ higher than that of comparable roughed-down sizes from conventionally cast ingots. This figure is nowadays confirmed by the many continuous casting machines in operation all over the world.

Other advantages of continuous casting are connected with the material flow. ${ }^{12)}$ Figure 2 is an illustration of material flows between melting shop and finished rolled product comparing conventional ingot casting and continuous casting. The continuous casting machine replaces several installations and may, under certain circumstances, even replace the universal ingot-slab mill, in particular, if a new iron and steelworks is being built and equipped with continuous casting facilities. Furthermore, continuous casting offers

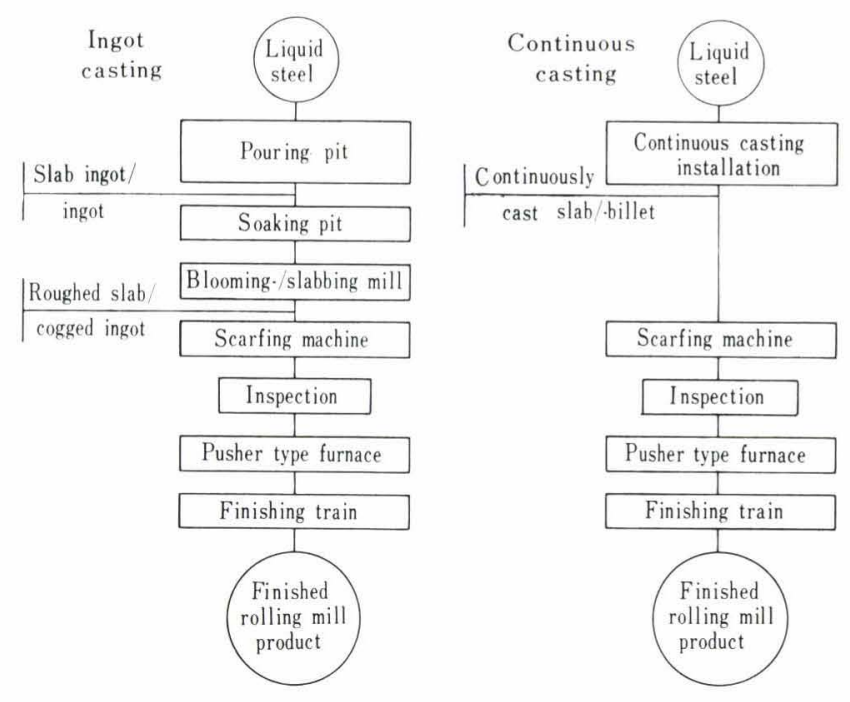

Fig. 2. Flow of material for ingot casting and for continuous casting

an ideal opportunity of applying the unit assembly system. While ingot-slab mills can only be run at low cost if the production is reasonably high, it is possible to provide economically working continuous casting capacities for practically any desired production. A later expansion of the production may be achieved quite simply by the addition of further continuous casting machines.

A survey of the advantages of continuous casting would be incomplete without the indication that only continuous casting has made it possible to meet the demand for practically any bloom and slab weight. Certain weights cannot be realised except by continuous casting.

Quite another factor in favour of continuous casting is the possibility to save manpower for the casting pit, which in the future will be more and more difficult to recruit.

At this point a short remark concerning the problem of rimmed or killed steels may be allowed. Regarding the yield, in conventional ingot casting rimmed steel clearly outmatches killed steel whereas, on the other hand, the considerable disadvantages of rimmed steel resulting from its susceptibility to segregation are well known. In continuous casting this problem does not exist. Both rimmed and killed steels have identical yields, and with regard to segregation, continuous casting is anyhow superior to conventional ingot casting. We believe that killed steel today is and will continue in the future to be the preferred steel for continuous casting.

Like others also, we have made tests in continuously casting rimmed steel. According to our observations this is not so much a matter of continuous casting, but rather a question of proper steel making practices. Considering the identity of yields we did not see any reason to proceed along this line, the more as meanwhile it has been proved that in contrast with current opinion, killed steel may successfully be used for practically all applications. 


\section{Comparison of Different Types of Continuous Casting Machines}

The continuous casting machines, on which today steel is being cast all over the world, have to be distinguished between the following four principal types in the order of their development: ${ }^{13)}$

the vertical type machine;

the vertical type machine with bending;

the circular bow-type machine; and

the oval bow-type machine.

Figure 3 shows a schematic drawing of a vertical type machine. The solidified strand is vertically cut by torch cutters running with the strand. The cut-off strand is subsequently shifted into the horizontal and removed.

The strand on a vertical machine with bending as shown in Fig. 4 is also cast straight but is being curved mostly in its solidified condition below the pinch rolls

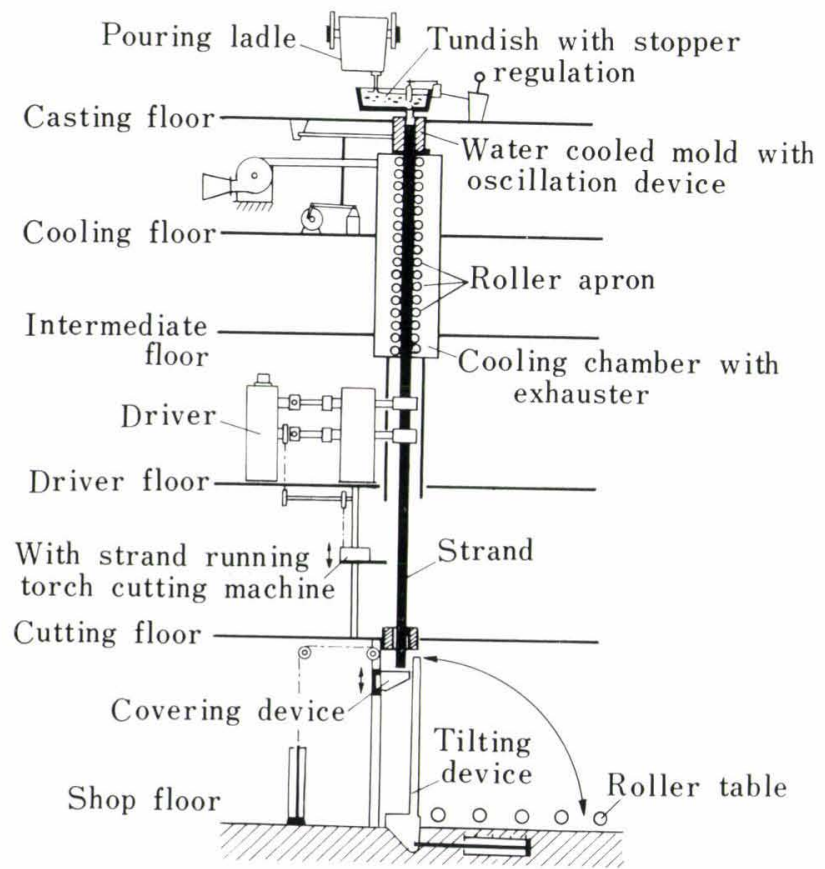

Fig. 3. Vertical type continuous casting machine

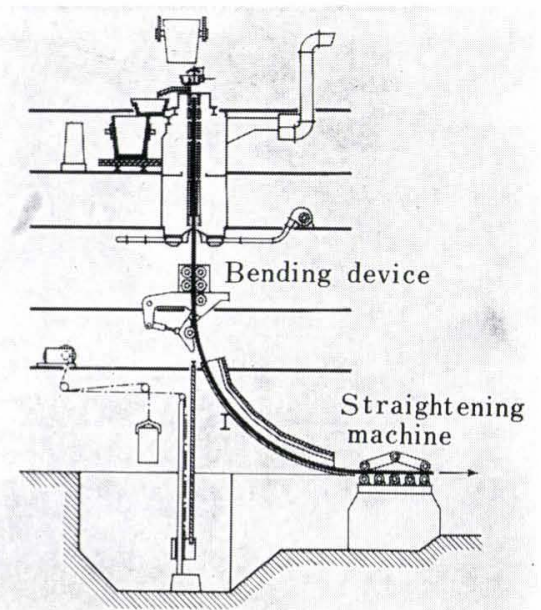

Fig. 4. Vertical type continuous casting machine with bending of the strand and, after having run through a quarter circle, is being straightened again and cut in the horizontal position.

The scheme of a circular bow-type machine is shown in Fig. 5. Without deformation of the still thin but already sufficiently strong shell, the strand leaves the mould as an arched section with a radius corresponding to that of the circular bow of the machine. Straightening is done, in most cases, by a conventional withdrawal machine, the so-called driver, or - as shown here-by the more and more asserting multi-roll drive, first tested and recommended by Mannesmann. Straightening can be done in either the solidified or not yet solidified condition. The strand is subsequently cut to size in the horizontal position.

Finally, Fig. 6 illustrates schematically an oval bowtype machine which may be considered as a development of the circular bow-tvpe machine. Just as in the latter, the strand is cast in an arched shape and then progressively straightened by passing through circular arcs with increasing radii. Straightening is preferably being done while the core is still liquid. Here the strand has also reached the horizontal position before it enters the withdrawal machine which in our opinion should be designed as a multi-roll drive.

Whether a vertical or a bow-type casting machine is appropriate, largely depends on the quality programme and the sections to be cast. For special sections, steel grades susceptible to deformation, certain high-grade steels and for hollow strands as basic material for the manufacture of seamless tubes, a vertical casting machine will often be chosen or - as in the case of the hollow strands-will have to be chosen. In this regard the vertical casting machine may fairly be considered the most universal type of machine. On the other hand, its most striking disadvantage should not be left unmentioned: the vertical machine does not

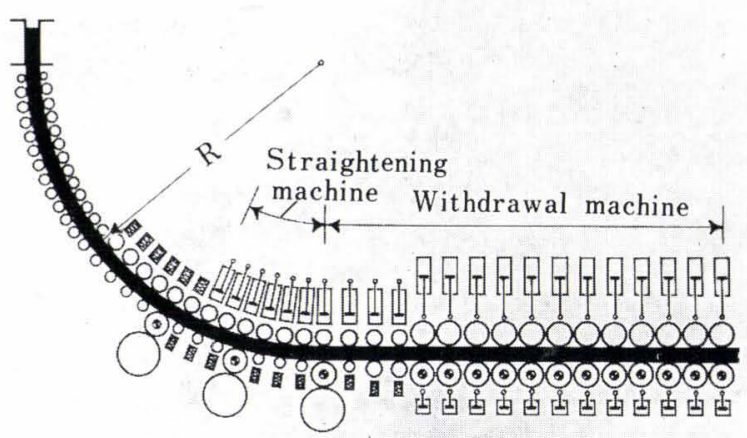

Fig. 5. Circular bow-type continuous casting machine

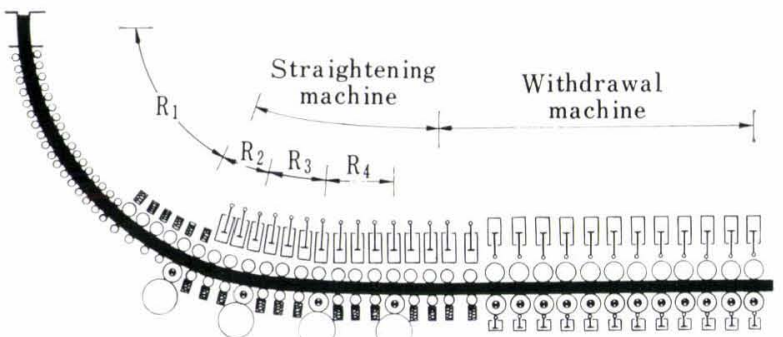

Fig. 6. Oval bow-type continuous casting machine 
allow the casting of endless strands. The bow-type casting machine will certainly be most adequate for the production of ordinary steel, e.g. of semis for wide flats as well as rectangular and square sections of soft and medium-hard unalloyed steels. Finally the available accommodation may determine the choice of a certain type of machine.

\section{Factors Affecting the Continuous Casting}

Certain technical parameters essentially effect the size and performance of a continuous casting machine. Casting speed and strand section determine the casting rate, while the casting time is calculated from the casting rate and the heat size. The maximum admissible casting time is, at first, determined by the fact that for metallurgical reasons the molten steel must be cast within a certain precisely adjustable temperature range, if no negative effects regarding surface condition and steel quality shall occur. The casting time is also limited by the life of the refractory material, especially for the plugs in ladle and tundish and the immersion nozzle.

Today stirring of steel in the ladle with inert gases, such as Argon, is an excellent means of controlling the casting temperature. Such stirring of steel in the ladle results in an equalization of temperature and reduces the temperature interval during casting as compared with that of untreated ladles. The stirring has the agreeable secondary effect of simultaneously improving the cleanlyness by flushing up suspended nonmetallic deoxidation-products

Whereas the problem of the casting temperature has thus been solved successfully, much research and development work remains to be done with regard to long wearing refractory products suitable for long casting times. Here is a key to further increase the performance of continuous casting machines and to improve the quality of the products made of continuously cast steel.

\section{Bases of Selection of Continuous Casting Machine}

\section{Fundamental Prerequisites}

The well-known question for the harmonic design of BOF-shops in combination with continuous casting plants, i.e. the ideal coordination of converter size and number of vessels blowing with the continuous casting machines required can be reduced to a nomogram as shown in Fig. 7.

The example given in Fig. 7 is based on 200-t converters. With an assumed casting rate of $4 \mathrm{t} / \mathrm{min}$, which in the case of slab casting, normally means two strands, the actual casting time is $50 \mathrm{~min}$. Considering a $30 \mathrm{~min}$ setting time, from the end of a casting operation to the beginning of the next, the total casting time will be $50+30=80 \mathrm{~min}$. In case of a tap to tap time of $40 \mathrm{~min}$ the heat frequency for one blowing converter also amounts to $40 \mathrm{~min}$ and is reduced to $20 \mathrm{~min}$ if there are two blowing converters.

As can be seen from the partial figure in the right upper corner of this graph, the number of continuous casting machines required is either 2 or 4 . The number of strands provided for each individual machine is determined by the sections to be cast and the casting speed.

\section{Vertical Casting Versus Bow Casting}

It is certainly well known that in the non-ferrous industry continuous casting on vertical casters had already advanced to a production basis, before this process made its way in the steel industry. Although the continuous casting of non-ferrous metals and steel is, on principle, comparable, there are some remarkable differences. These differences are due to diverging

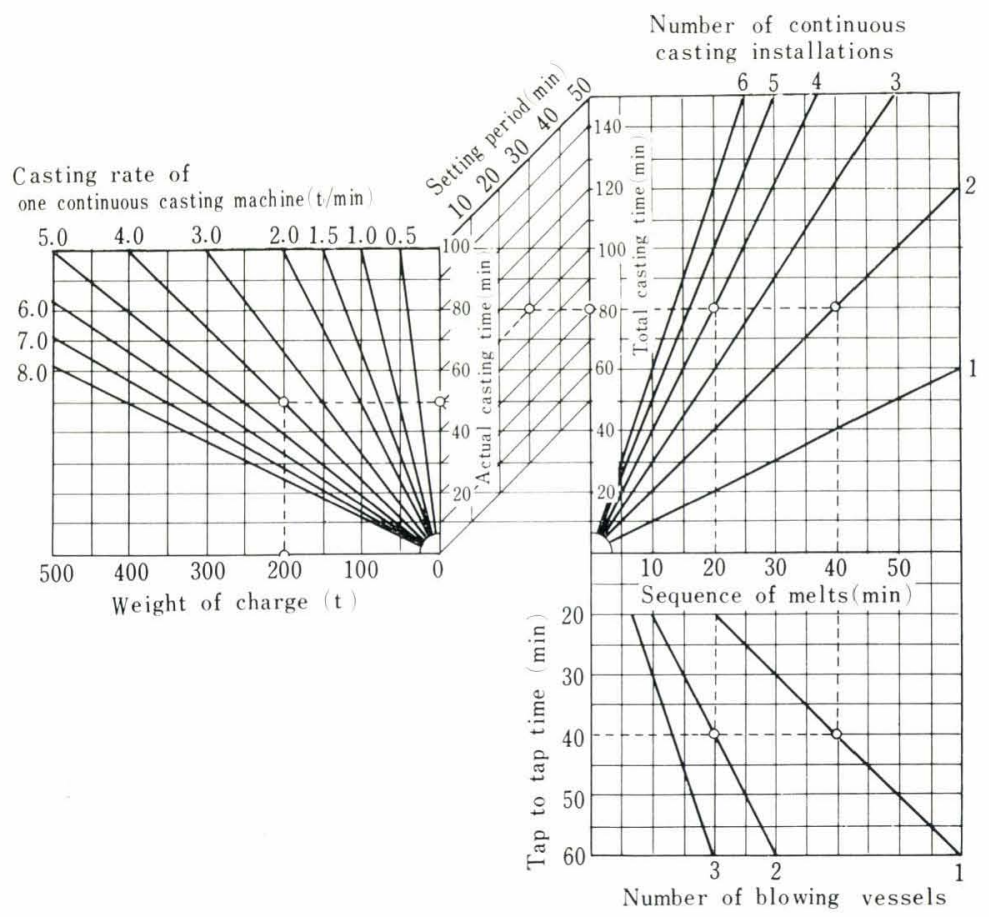

Fig. 7.

Nomograph for the determination of the optimal layout of BOF-shops with continuous casting installations 
properties of non-ferrous metals and steel. ${ }^{14)}$

Steel is characterized by its high melting point and its relatively low temperature conductivity. The ratio of the temperature conductivities of steel, aluminium and copper are 1:11:13 respectively. The necessity of casting big steel quantities within a relatively short time asks for high casting speeds. Such high casting speeds together with the slow solidification of the steel lead to great pool depths. It is quite obvious that the liquid core is equally getting deeper with growing casting sections and increasing casting speeds. With a comparable secondary cooling the liquid core tends to be even larger in the rectangular slab sections than in square sections of equal thickness because the ratio of cooled surface to volume is smaller.

Consequently, with increasing casting sections, casting rates and equally increasing pool depths, vertical casters would tend to be higher and higher and would reach dimensions which are technically and economically no longer practicable. In order to substantially decrease the overall height, the strand was given a certain curvature. In this case it is, of course, preferable to use a curved mould, so that the strand, while its shell is still thin and of inadequate strength, need not to be subject to inadmissible bending stresses. The bow casting system has meanwhile asserted itself all over the world.

On the other hand, the strand cast on such bow casters must subsequently be straightened. If, in relation to the section to be cast, the curvature radii are sufficiently great, such straightening is done with the strand being fully solidified; this holds good, in particular, for most of the older machines in the world. While, in itself, this principle is valuable, the increasing casting rates would cause the distance between mould and straightening machine to become longer resulting in increasing overall plant height. By stepping up casting speeds, it becomes necessary to straighten the partly solidified strand-with its core still molten. In that case, we feel that straightening should not be done in one single step, as in the circular bow caster, but in several steps, which method involves less strain on the strand.

The bending stresses with their possible injurious effects, such as inside or outside transverse cracks, ${ }^{15}$ ) are smaller for each step in the oval bow caster than in single-step straightening of the circular bow caster. Also, straightening of the strand may be initiated at higher temperatures, so that temperature ranges that are critical for deformation can be more easily avoided.

The overall height of a vertical caster exclusively depends on the length of the liquid pool. In the circular bow caster the casting radius is generally determined on the basis of the admissible deformation of the outside fiber of the strand shell. Assuming this to be $1 \%$, the casting radius for a slab thickness of $250 \mathrm{~mm}$ would be about $12 \mathrm{~m}$. Depending on the number of straightening steps, the casting radius of the oval bow caster can be reduced almost at random, though, for technical reasons, the lower limit is somewhere around $3 \mathrm{~m}$. Apart from that, the deformation at the phase boundary liquid-solid cannot be neglected as an essential criterion in either bending or straightening.

\section{Strand Withdrawal Driver}

The drive to withdraw the cast strand which is generally used in vertical and circular bow-type casters consists of two to three pairs of rollers, the so-called driver, which are pressed against the strand with very high forces. These rolls must furnish the total withdrawal force; that means that, starting from the mould, the strand withdrawal force increases continuously until it is-within an extremely small range-completely eliminated by the driver.

In contrast with the standard drive so far used in continuous casting, the multi-roll drive developed by Mannesmann makes it possible to start driving the strand already within the range of the liquid pool. ${ }^{16}$ ) The contact forces of the driven rollers acting on the strand can be kept so small that no strand defects are caused. Ideally, the number of driven rolis may be so increased that the loading on the apron rollers as caused by the ferrostatic pressure will be sufficient to transfer the torque. Another advantage of the multiroll drive is the fact that the drive may start right below the mould, so that the withdrawal loading on the strand shell may already be eliminated before it reaches a critical value and may even be reversed into a compressive load. This would provide the additional advantage that a relatively short dummy bar may be used. In order to avoid an unequal loading of the slab strand with its still liquid core, it should be ensured that the power of the drive is transmitted as uniformly as possible to the top and bottom faces of the strand. The effect of a multi-roll drive on a slab of $200 \mathrm{~mm}$ thickness at casting speeds of $1 \mathrm{~m} / \mathrm{min}$ and $1.5 \mathrm{~m} / \mathrm{min}$ is shown in Fig. 8 for the circular and oval bow-type machine. As can be seen, the stress can be kept very small.

\section{Other Advanced Techniques}

In addition to the technical aspects of the machine properties and its conception which cannot for ever remain up to date, the operational aspects are equally important. If, today, nobody is talking any more of the breakouts that, in the early times of continuous casting, caused such grievous losses in production, and if breakout rates far below $1 \%$ are now the accepted rule for a well-kept plant, this is not in the last instance due to improved mould designs and the complete control over the secondary cooling with spray water as well as to the possibility of perfect alignment of the machine. By abandoning casting with oil and its substitution by powder casting with immersed nozzles, a great progress was achieved. This not only improved the strand surface, but also decreased considerably the breakout rate.

Casting powder is nowadays a generally accepted and almost classical casting aid in the continuous casting of heavy rectangular and slab sections. Two trends of development have been followed: the casting under heavy fusing powders and the casting under such powders forming low melting slags which flow out to- 


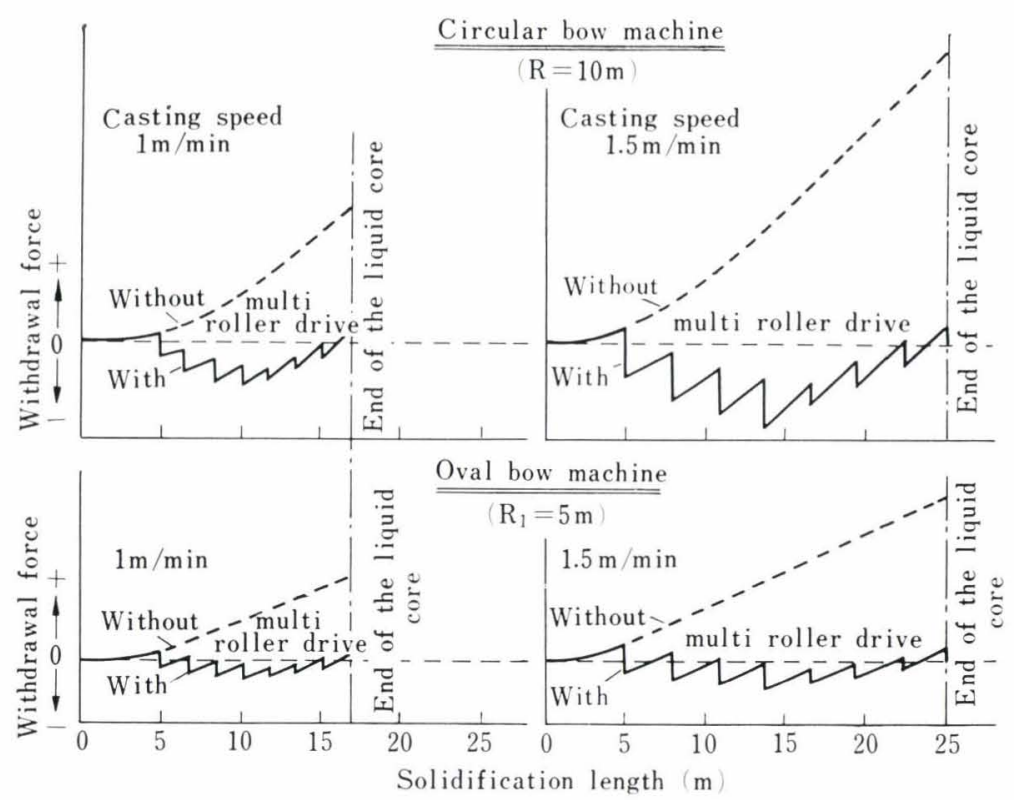

Fig. 8. Working of the multi roller drive for a slab thickness of $200 \mathrm{~mm}$

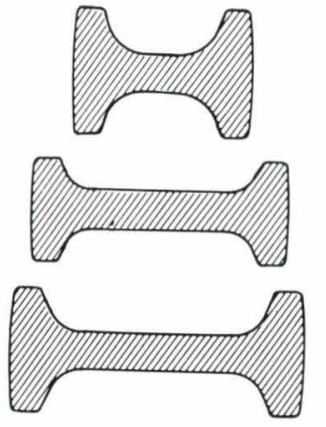

Fig. 9. Cross section of continuously cast preshaped profiles (DOG BONES) gether with the strand and peel off after solidification. The use of immersed nozzles was an essential condition for the casting under powders that form readily fusing slags. By means of these nozzles the steel flows from the tundish through a closed system below the meniscus in the mould. This procedure avoids slag inclusions in the strand which, with open casting operation, are carried forward with the steel and retained by the solidifying strand.

Nevertheless it cannot be entirely avoided that slag patches rest attached to the strand surface and may cause defects during subsequent rolling. In many cases, an inspection of the strands in their as cast condition together with local conditioning of such areas may be sufficient. In order to assure the detection and elimination of all defects by conditioning, it is advisable to scarf the strands from all sides with the resulting additional advantage that thus even slag inclusions just below the surface and other non-metallic inclusions are removed. Scarfing machines of modern design are capable of producing - even for wide slabsabsolutely smooth surfaces. They also allow the variation of the scarfing power within wide limits down to a minimum reduction. In its Huckingen iron and steelworks, Mannesmann makes the most generous use of this possibility. By the scarfing itself and the adjustment of the scarfing power to the subsequent applications not only the best possible yield is ensured, but also the certainty of supplying unobjectionable continuously cast material to the processing divisions.

The scarfing and conditioning losses tend to decrease as the surface to volume ratio decreases or, in other words, as the cast sections increase in size. This is one more reason, scarfing should best be done on the strand in its as cast condition, and not on an intermediate size during rolling.

Primary sections for heavy sectional steel, such as wide-flange beams or I-beams may be directly produced on the continuous casting machine. ${ }^{17), 18)}$ Figure 9 shows some examples of such primary sections which are known by the rather appropriate term " dog bones." Of course, for quality reasons a sufficient degree of reduction during subsequent rolling must be granted.

In view of the idea to obtain several initial pass sections for the subsequent rolling mills from one primary section, it has been suggested to do part of the shaping in a rolling mill directly combined with the continuous caster. ${ }^{19)}$ Although this is, in some places, done and may, in special cases, even be justified, the direct combination of continuous casting and rolling is not, generally speaking, an altogether convincing solution, as the subsequent rolling mill is bound to work at a relatively low rate without being exploited to its full capacity. Besides, multi-strand casters which are widely used today and certainly will be the standard equipment of the future would require one rolling mill per strand and the capital expenditure involved would be out of proportion to the realizable performance.

\section{Harmonic Combination of Steelmaking and Continuous Casting}

To combine steelmaking and continuous casting, two approaches seem to offer an ideal and harmonic solution: basic-oxygen steelmaking/continuous casting, and high-capacity electric arc furnace/continuous casting. While the first combination has already proved successful the second will surely stand the test, once the plans now cherished all over the world will come to bear, i.e. once steel will increasingly be produced from sponge iron directly in a continuous process in highcapacity electric furnaces with high transformer capacities bypassing the classical blast furnace and BOF process. ${ }^{20), 21)}$ 
The catchword "electric arc furnace" gives rise to a retrospect of the past development of the continuous casting of steel. At the beginning, it was mainly special steel which was produced in relatively small electric arc furnaces and cast in strands. The real success in continuous casting came when big steel quantities from big heats were cast in strands. In fact, many problems concerning steel temperature and steel quality are simplified in casting big heats. Early difficulties in process engineering and design are today well under control. Looking back and in view of the experience gained in the continuous casting of big heats, it may be said that continuous casting is particularly indicated for the big sections of mass production.

\section{Sequence Casting}

While the preceding statements regard the continuous casting of one single heat, it is also possible to cast several heats sequently. The principal results are: improved performance by reduction of setting time in favour of actual casting time, and improved yield, by generating less scrap from all the heats cast in one sequence. Furthermore better heat equilibrium of the machine is achieved. Apart from the fact that sequence casting is still limited by the life of the refractory materials, in particular of plugs and nozzles, heat weights and lot sizes also exercise an influence. While for single-purpose steelworks sequence casting will always be the best solution - even with increasing heat weights and provided a satisfactory solution of the refractory material problems - in all other cases the advantages of sequence casting will diminish as heat weights are stepped up. Five 40-t heats cast in succession do not yield more steel than one single heat of $200 \mathrm{t}$.

\section{Future of Continuous Casting}

Although by no means complete and leaving of course many questions open, this should be a sufficient description of the actual state of continuous casting of steel, leading us to aspects of its future development which we should see without loosing the reality of today. At first the rather trivial and on principle uncontradicted statement should be mentioned that continuous casting will continue expanding. As regards the number of continuous casting plants in operation, we have, over the past years, only witnessed the beginning of the development. The same is true of the plurality of steel qualities to be cast.

It remains to be seen whether the ideal continuous casting plants of the future will resemble those in operation today. The unforeseeable future development may eventually lead to new conceptions. Such a new conception could, for instance, consist of the combination in one plant of the advantages the different types of machines have in themselves.

The research and development work now under way with regard to the construction of continuous casting machines and the metallurgy of continuous casting of steel will, without doubt, eliminate existing uncer- tainties and expand the ficlds of application of continuous casting.

When building new iron and steelworks or modernizing old ones, continuous casting will have to be, right from the beginning, one subject matter of the planning; and this not only for a part, but for the whole steel production. First approaches in this direction can already be observed. Whereas in the conventional design of a steelmaking plant with conventional ingot casting, the casting shop is adapted to the existing situation in the melting shop, the incorporation of continuous casting requires the full consideration of all melting and casting data and of their reciprocal effects, in order to achieve the most favourable design. But not only the techniques of steelmaking, but also those of the rolling mills must be adjusted to the special features of continuous casting.

It remains to be seen, whether an integrated iron and steel mill should really be operated fully continucusly. If so-and although this may, for the time being, only be possible in certain parts of the mill, for instance the steelmaking or the rolling continuous casting would in any case constitute an important component part. Continuous steelmaking is not, in the long run, practicable without the combination with continuous casting and this regardless of whether steel is being produced from pig iron leaving the blast furnace or from sponge iron from the direct reduction plant.

Perhaps the idea proceeds, not to transport raw materials over long distances but, instead, semi-finished products manufactured next to the raw material sources by the locally most adequate process and in sections that do not restrict later applications. Here again, continuous casting recommends itself as the ideal means of producing semis of dimensional accuracy, easily to be handled and of long length that can be cut to size by the consumer himself. An intermediate stock yard with such long strands of well assorted qualities and cross-sections may be kept much smaller and more flexible than a yard with semis from conventionally cast ingots. The handling of the long strands would, of course, require the design and application of special equipment.

Even if only considering the nearer future, the automation of the continuous casting process can certainly be expected within the next decade. Valuable preliminary work has already been done so that this expectation is not altogether an Utopian idea.

As well as the casting of primary sections the casting of hollow sections for the manufacture of seamless tubes is also rather close to its industrial application. With piercing being no longer part of the shaping process, but included into the casting phase, the limitation of bloom sizes and, consequently, of tube lengths effected by the thermal stress or by the mechanical stability of the piercing tools is eliminated; this allowing the production of tubes of considerably extended lengths. Thus not only the technical shaping problems are shirked, but other disadvantages are also eliminated which result from the dislocation of the internal loose- 
ness in the solid bloom towards inside the wall of the hollow body. In the hollow casting any existing internal looseness will be well inside the wall of the hollow body, as solidification starts from both the inside and outside surfaces. In no case they are cut during the subsequent manufacturing operations so that neither the internal surface quality nor the stress resistance of the finished tube are impaired.

These few outlooks into the future together with the present state of the continuous casting of steel show that we are witnessing a development which offers many advantages for metallurgical techniques and the profitability of steelmaking. We should endeavour to make the fullest possible use of these advantages.

\section{Summary}

Today continuous casting of steel has succeeded to take a firm place among the metallurgical processes. Its development can, however, not yet be considered as completed. Nevertheless, if the experiment is made to report about the actual state and the future development of the continuous casting of steel, this is based on the long standing development work and experience with the casting of almost 5 million tons of steel, which since 1962 have been produced in the continuous casting machines of Mannesmann. A general view of the existing machines and the wide ranging program of steel grades informs about the actual state.

The advantages of continuous casting with regard to steel quality, yield and material flow are described and possibilities of rationalization, questions of the design of continuous casting machines and their harmonic integration in steelworks are discussed. The different types of continuous casting machines today in operation are compared. The forces acting on the strand during casting are outlined. The importance of multi-roll drives and the reduction of the withdrawal forces hereby attained as well as the careful treatment of the strands are explained.

Technical points of view for the working capacity of continuous casting machines, as breakouts, mold construction, strand cooling and the casting under powders with submerged nozzles are discussed as well as questions concerning scarfing.

In the final view to future developments questions concerning automation, conclusions for the future design of continuous casting machines and the casting of hollow strands for the fabrication of seamless tubes are discussed.

\section{REFERENGES}

1) Economic Aspects of Continuous Casting of Steel, United Nations Publication New York (1968), Sales Number: 68. II. E/Mim. 19

2) Continuous Casting of Steel, Spec. Report, Iron Steel Inst.,
No. 89 (1965), London.

3) M. S. Bojcenko, V.S. Rutes, and N. A. Nikolaev: Continuous Casting of Steel (Nepreryvnaja raslioka stali), (1957), Moskow.

4) K. G. Speith and A. Bungeroth: Das Stranggießen von Stahl nach dem Junghans-Verfahren, Stahl u. Eisen, 72 (1952), 869.

5) K. G. Speith and A. Bungeroth: The Junghans' Method of Continuous Casting of Steel, Metal Treatment and Drop Forging, May/June, (1953).

6) K. G. Speith: Observations on the Continuous Casting of Steel, Engenharia, Mineracao e Metalurgia, Jan./Feb., (1954).

7) K. G. Speith and A. Bungeroth: Über die Entwicklung des Senkrecht-Stranggusses von Stahl, Stahl u. Eisen, 76 (1956), 437.

8) K. G. Speith and A. Bungeroth: Erfahrungen mit Stranggießen von Stahl in der Bundesrepublik Deutschland, Revue Universelle des Mines, 14 (1958), 649.

9) K. G. Speith and A. Bungeroth: Continuous Casting of Steel in Western Germany, JISI, 190 (1958), 158, 435.

10) U. Petersen, K. G. Speith, and A. Bungeroth: Über die Entwicklung des Stranggießens von Stahl und seine großtechnische Anwendung, Stahl u. Eisen, 86 (1966), 333.

11) H. Kobusch and H. Schrewe: Five Years Experience with Continuous Casting of Wide Slabs, Open Hearth Proc., (1968), 118.

12) U. Petersen: Das Gießen von Stahl in StranggießanlagenMöglichkeiten zur rationellen Produktion und Produktionsteilung. Report No. 102 of the Arbeitsgemeinschaft für Rationalisierung des Landes Nordrhein-Westfalen, Verkehrs- und Wirtschaftsverlag Dr. Borgmann, Dortmund, (1969).

13) K. G. Speith, A. Bungeroth, and H. vom Ende: The Continuous Casting of Steel in Vertical and Curved Mold Machines, Journal of Meials, (1966), 609.

14) H. vom Ende and K. G. Speith: Stranggießen von Stahl. Z. Metallk., 60 (1969), 2.58.

15) A. Bungeroth and H. vom Ende: De certains défauts possibles dans les produits obtenus par coulée continue, Rev. Mét., (Jan. 1968), 35.

16) H. Schrewe and G. Vogt: Strand Support and Strand Withdrawal during the Casting of Slabs using the Mannesmann Multi-roll Drive, 53rd $\mathrm{NOH}$ and BOS-Conference AIME, Detroit, April 6 to 8, 1970.

17) J. Pearson: Discussion remarks in: Continuous Casting of Steel, Spec. Rep., Iron Steel Inst., No. 89 (1965), 88, London.

18) G. S. Lucenti: The Continuous Casting of Beam Blanks at the Algoma Steel Corporation Ltd., Blast Furnace and Steel Plant, (1970), 19.

19) B. Tarmann and H. Vonbank: Das BSR-Verfahren-eine Ergänzung zum Stranggießen von Stahl, Radex-Rundschau, (1967), 429.

20) U. Kalla, H.-D. Pantke, and K. Pittel: Vergleich der technischen Kennzahlen und der Wirtschaftlichkeit bei der Herstellung und Verarbeitung von Eisenschwamm, Stahl $u$. Eisen, 87 (1967), 534.

21) J. Mackenzie: The Future Role of Directly Reduced Iron, JISI, 207 (1969), 765 